\title{
Linking Diabetes mellitus to SARS-CoV-2 infection through differential targeting of the microRNAs in the Pancreas tissue
}

\author{
Bhavya, Ekta Pathak*, and Rajeev Mishra*, \\ Bioinformatics Department, MMV, Institute of Science, Banaras Hindu University, Varanasi- \\ 221005, India. \\ * To whom correspondence should be addressed: \\ Dr. Rajeev Mishra, Associate Professor in Bioinformatics, MMV, Institute of Science, \\ Banaras Hindu University, Varanasi-221005, India. Tel: +91 9935338891, \\ rajeev17@bhu.ac.in; \\ Dr. Ekta Pathak, PhD in Bioinformatics, MMV, Institute of Science, Banaras Hindu \\ University, India. Tel: +91 9651709839, ektavpathak@gmail.com
}

\begin{abstract}
Coronavirus Disease 2019 (COVID-19) severity and Diabetes mellitus affect each other bidirectionally. The plus-sense single-stranded RNA (+ssRNA) genome of the SARS-CoV-2 virus can be targeted and suppressed by the host cell's microRNAs (miRNAs). Using the differential gene expression analysis between the mock-infected and the SARS-CoV-2infected pancreatic tissue, we report five Diabetes-associated genes that are upregulated due to SARS-CoV-2 infection in the hESC pancreas tissues. Ten miRNAs regulating these five genes can potentially target the SARS-CoV-2 genome. We hypothesize that the SARS-CoV-2 genome copies in the infected human pancreas cell compete with the host cell's native genes in being regulated by the native miRNAs. It leads to the reduced miRNA-regulation and, thus, the upregulation of the Diabetes-associated native genes. Thus, the resultant new-onset or elevated Diabetic symptoms may worsen the condition of COVID-19 patients.
\end{abstract}

Keywords: COVID-19, SARS-CoV-2, Diabetes mellitus, miRNAs, Gene-gene interaction 


\section{Introduction}

Coronavirus Disease (COVID-19) is a fast-spreading disease that has caused a global crisis. This pandemic is a highly infectious viral disease caused by Severe Acute Respiratory Syndrome Coronavirus 2 (SARS-CoV-2), also known as novel coronavirus-2019 [1, 2]. According to the World Health Organization's (WHO's) COVID-19 Dashboard [3], $110,749,023$ cases and 2,455,131 deaths have been reported globally due to COVID-19 as of $21^{\text {st }}$ February 2021. SARS-CoV-2 has a positive-sense single-stranded ribonucleic acid (+ssRNA) genome enclosed in a protein-containing lipid bilayer [4, 5]. Its RNA genome acts as a messenger RNA (mRNA) after entering the host cell and is directly translated by the host cell's ribosomes, resulting in viral proteins. These translated viral proteins are also responsible for viral RNA replication [6].

Patients having either type 1 or type 2 Diabetes mellitus (commonly referred to as Diabetes) show poor prognosis with SARS-CoV-2 infection due to blood glucose level fluctuations and metabolic complications. An increase in blood glucose level helps in the SARS-CoV-2 replication and proliferation in the human monocytes [5, 7]. New-onset Diabetes has also been observed after COVID-19 infection [8]. Thus, COVID-19 severity and Diabetes affect each other in a bidirectional manner. Moreover, the resultant hyperglycaemia can diminish the individual's immune response towards handling the viral infection. COVID-19 mortality is also amplified for diabetic patients due to complications like cardiovascular diseases and kidney-related problems [8-11]. Thus, regulating the blood glucose levels and preventing diabetic complications is required for diabetic COVID-19 patients to avert severe consequences of the infection on them [5].

Autopsy reports have been known to reveal COVID-19 infection in the human pancreas [12]. It becomes possible due to the angiotensin-converting enzyme 2 (ACE2) receptors on the pancreas cells. ACE2 acts as a very high-affinity receptor on the cell for the spike protein of SARS-CoV-2 [13, 14]. MicroRNAs (miRNAs) play an essential role in the regulation of gene expression in a cell. In a virus-infected cell, the host cell's miRNAs help in cell defense by targeting the viral RNA genome or its transcribed RNAs. In humans, the miRNAs mostly target the 3'UTR of the mRNAs. However, the miRNAs primarily target the 3'UTR and 5'UTR of the viral RNA genomes. During a viral infection, the host cell's miRNAs may target the viral genome rather than the native mRNAs. It leads to a competition for miRNA regulation between the host cell's mRNAs and the viral genome copies in the cell. This 
differential targeting of the miRNAs may result in the dysregulation of the host cell's genes [15-18].

In this study, we hypothesize the link between Diabetes and COVID-19 through differential targeting of the miRNAs in the Pancreas tissue. The disease enrichment based on differential gene expression analysis revealed pancreas- and diabetes-associated terms. We identified the miRNAs that can potentially target the SARS-CoV-2 genome as well as the Diabetesassociated genes upregulated in SARS-CoV-2-infected pancreas tissue.

\section{Materials and Methods}

Differential gene expression analysis - The RNA-Seq gene expression data for mockinfected and SARS-CoV-2-infected hESC pancreatic tissue were retrieved from NCBI. For the study, three mock-infected and three SARS-CoV-2-infected hESC pancreatic tissue samples were chosen from the Gene Expression Omnibus (GEO) dataset accession, GSE151803 [19]. The Differentially Expressed Genes (DEGs) between the mock-infected and the SARS-CoV-2-infected pancreatic tissue were obtained using the DESeq2 R package (padj < 0.05 and $|\log 2 \mathrm{FC}|>1$ ) [20, 21].

Disease enrichment analysis - DEGs-based disease enrichment analysis was done through DAVID - Functional Annotation Tool considering the Gene-Disease Associations Dataset (GAD) $[22,23]$. The pancreas-associated diseases and the DEGs associated with them were selected for further studies. A literature search was done for the obtained DEGs to understand their role in the respective diseases.

Gene-gene interaction network - The gene-gene interaction (GGI) network of the DEGs was created using the Cytoscape-GeneMANIA app [24-26]. Network topological analysis was done using the Cytoscape-NetworkAnalyzer plugin [27] to get an insight about the influence of the genes in the network.

Differentially targeting miRNAs - The complete genome reference sequence of SARSCoV-2, Wuhan-Hu-1, was retrieved from NCBI RefSeq ID, NC_045512.2 [28]. The 3'UTR and 5'UTR of the viral genome were obtained. The human miRNAs targeting the 3 ' and 5' UTR of the SARS-CoV-2 genome (CoV-tar-miRNAs) were obtained using the miRDB 
online tool $[29,30]$. The target genes of CoV-tar-miRNAs were obtained using the Predicted Target Module of miRWalk 2.0 [31, 32].

Diabetes-linked CoV-tar-miRNAs - The target genes of the CoV-tar-miRNAs were compared to the enriched Diabetes-associated genes. The genes common in both were those Diabetes-associated genes that may get upregulated in pancreas cells due to miRNAs' differential targeting during SARS-CoV-2 infection. Furthermore, the availability of miRNAs in the pancreas tissue was checked from the web-based repository, Tissue-Atlas [33].

\section{Results}

\section{Differential Gene Expression between mock-infected and SARS-CoV-2-infected}

pancreatic tissue - Using the DESeq2 R package, 30 differentially expressed genes (DEGs) between the mock-infected and SARS-CoV-2-infected pancreatic tissues of the GEO dataset GSE151803 were revealed [19-21]. 26 DEGs were upregulated and 4 DEGs were downregulated (Table 1) in the SARS-CoV-2-infected hESC pancreas tissue.

Disease enrichment of DEGs - DAVID Tool was used for DEGs-based disease enrichment analysis based on the Gene-Disease Associations Dataset (GAD) [22, 23]. Gene-based disease enrichment of the 30 DEGs resulted in Type I Diabetes as the most significant GAD disease. It was linked to four upregulated DEGs, i.e., CP, SOCS3, AGT and PSMB8 (Table 2). Two upregulated DEGs, CP and CFB were enriched for the term "insulin." COVID-19 has been linked with the other resultant disease terms, but only the terms associated with the pancreas were selected for the study.

Gene-Gene interaction (GGI) network - The Cytoscape-GeneMANIA [24-26] GGI network of the DEGs contains 29 genes as HCP5 is a lncRNA, and its data is not present in GeneMANIA. Diabetes-associated (Type 1 Diabetes and insulin-associated) DEGs are connected directly or indirectly through co-expression (Figure 1, Table 3). Two downregulated DEGs, i.e., AKR1B10 and PKHD1L1, show interaction with the upregulated DEGs (Figure 1, Table 4).

After removing the duplicate edges between the gene nodes, the network's topological parameters were calculated (Table 5). Closeness centralities of the SUCNR1 and TACR1 genes were ignored due to their interaction with each other only and not with the significant 
network. The Diabetes-associated gene CP has the highest closeness and betweenness centrality; thus, it is the most influential gene in the network. The CFB gene is the secondhighest diabetes-associated gene in terms of closeness centrality.

3'UTR and 5'UTR of the viral genome - The SARS-CoV-2 genome consists of a linear 29903 nucleotides long ss-RNA [28]. The 3'UTR of the genome is 229 nucleotides long, including a polyA tail. It lies in the viral genome at the position from 29675 to 29903 nucleotides. The 5'UTR of the genome is 265 nucleotides long and spans from 1 to 265 nucleotides in the viral genome. Both 3'UTR and 5'UTR of the SARS-CoV-2 genome sequence is appended below:

>NC_045512.2:29675-29903 Severe acute respiratory syndrome coronavirus 2 isolate Wuhan-Hu-1, complete genome

CAATCTTTAATCAGTGTGTAACATTAGGGAGGACTTGAAAGAGCCACCACATTTTCACCGAGGCCACGCG GAGTACGATCGAGTGTACAGTGAACAATGCTAGGGAGAGCTGCCTATATGGAAGAGCCCTAATGTGTAAA ATTAATTTTAGTAGTGCTATCCCCATGTGATTTTAATAGCTTCTTAGGAGAATGACAAAAAAAAAAAAAA AAAAAAAAAAAAAAAAAAA

>NC_045512.2:1-265 Severe acute respiratory syndrome coronavirus 2 isolate Wuhan-Hu-1, complete genome ATTAAAGGTTTATACCTTCCCAGGTAACAAACCAACCAACTTTCGATCTCTTGTAGATCTGTTCTCTAAA CGAACTTTAAAATCTGTGTGGCTGTCACTCGGCTGCATGCTTAGTGCACTCACGCAGTATAATTAATAAC TAATTACTGTCGTTGACAGGACACGAGTAACTCGTCTATCTTCTGCAGGCTGCTTACGGTTTCGTCCGTG TTGCAGCCGATCATCAGCACATCTAGGTTTCGTCCGGGTGTGACCGAAAGGTAAG

miRNAs targeting the UTRs of the viral genome - Using miRWalk 2.0 online tool [31, 32], 10 and 11 miRNAs, i.e., CoV-tar-miRNAs, were found to be potentially targeting the 3'UTR (Table 6) and 5'UTR (Table 7) of the SARS-CoV-2 genome, respectively.

CoV-tar-miRNAs targeting Diabetes-associated DEGs - Each of the five Diabetesassociated DEGs was found to be targeted by one or more CoV-tar-miRNAs. Eight 3'UTR and nine 5'UTR CoV-tar-miRNAs were found to be potentially targeting the Diabetesassociated DEGs, respectively. Availability and raw microarray expression of five 3'UTR and six 5'UTR CoV-tar-miRNAs in the human pancreas were obtained from the TissueAtlas webbased repository. Due to the microarray expression data's unavailability in TissueAtlas, hsamiR-466, hsa-miR-3123, hsa-miR-4691-3p, hsa-miR-3941, hsa-miR-6749-3p and hsa-miR7851-3p were not considered for further study. hsa-mir-4775 has a negative raw microarray 
expression value in the human pancreas; thus, it was also not considered for differential targeting analysis. Four 3'UTR and six 5'UTR CoV-tar-miRNAs are expressed in the human pancreas (Table 8).

\section{Discussion}

The SARS-CoV-2 infection has been detected in many different human organs, including the pancreas. The viral infection may lead to dysregulation of genes in the infected cells. 26 and 4 genes were found to be upregulated and downregulated, respectively, in the SARS-CoV-2infected hESC pancreas tissue. Among them, five upregulated genes, i.e., CP, SOCS3, AGT, PSMB8, and CFB, are associated with Diabetes (Type 1 Diabetes or insulin). Among the genes associated with other enriched diseases, six upregulated genes, i.e., CP, AGT, CFB, SERPINA3, CXCL2, and C8B, encode for proteins that are secreted to blood. These proteins may also reach other organs of the body, thus, being involved in other diseases. Their roles in other diseases must be further investigated. Diabetes can result in Nephropathy or Macular Degeneration [34-36]; therefore, they can be the indirect results of COVID-19.

The human miRNAs mostly target the 3'UTR of the mRNAs in the cytoplasm of the cell. However, they primarily target the 3'UTR and 5'UTR of the infecting viral RNA genome. It has been seen that the SARS-CoV-2 virus also infects the pancreas, among other organs of the human body. Since it is a +ss-RNA genome virus, its genome itself acts as an mRNA. Thus, the pancreas cell's miRNAs must target the viral 3'UTR or 5'UTR, causing them to deflect from regulating the pancreas host cell's native genes. This may cause the upregulation of the host cell's native genes. Twenty-one human miRNAs (CoV-tar-miRNAs) were found to be potentially targeting the UTRs of the viral genome. Considering the availability of these miRNAs in the human pancreas tissue, 10 of them also target the Diabetes-associated genes, thus, keeping their expression in check before the infection. After infection, the SARS-CoV-2 genome competes with the mRNAs of these genes in being targeted and regulated by the miRNAs. This differential targeting of the miRNAs explains the upregulation of the Diabetes-associated genes after the viral infection (Figure 2).

The SOCS3 (Suppressor of Cytokine Signaling 3) gene codes for a protein that helps regulate cytokine signal transduction [37]. It is the potential target of four 3'UTR CoV-tar-miRNAs, i.e., hsa-miR-1236-3p, hsa-miR-4279, hsa-miR-4717-3p and hsa-miR-5088-5p, and two 
5'UTR CoV-tar-miRNAs, i.e., hsa-miR-1303 and hsa-miR-3925-5p. Thus, SOCS3 upregulation after the viral infection may be due to the differential targeting of these miRNAs. Overexpression of SOCS3 has been observed in mice having Type 1 Diabetes. SOCS3-deficiency in pancreas beta cells is associated with increased resistance to apoptosis, thus, preventing Type 1 Diabetes [38]. However, in the SARS-CoV-2- infected Pancreas tissue, the expression of SOCS3 may be increased due to differential targeting of miRNAs; thus, it decreases the beta cells' resistance to the development of Diabetes.

The PSMB8 gene is the potential target of three 3'UTR CoV-tar-miRNAs, i.e., hsa-miR1236-3p, hsa-miR-4279 and hsa-miR-5088-5p, and two 5'UTR CoV-tar-miRNAs, i.e., hsamiR-3925-5p and hsa-miR-298. PSMB8 codes for Proteasome 20S Subunit Beta 8 and has been found to promote apoptosis [39, 40]. Its upregulation may also contribute to the apoptosis of the pancreas' beta cells.

The CP gene is the potential target of two 5'UTR CoV-tar-miRNAs, i.e., hsa-miR-4747-5p and hsa-miR-5196-5p. The CP gene encodes a secretory plasma protein called Ceruloplasmin, the level of which is found to be increased in the Diabetic condition [41]. CP has the highest closeness and betweenness centrality, indicating its strong influence on the network.

The CFB gene encodes for the secretory complement factor $b$, which links obesity to Diabetes. Its level is found to be increased during obesity. It is also linked to insulin resistance [42]. Although in our study, CFB gene expression does not seem to be affected by differential miRNAs targeting, its upregulation is linked with the upregulation of CP, SOCS3, and AGT genes as all these genes are co-expressed according to the gene-gene interaction network (Figure 1).

The AGT gene is the potential target of three 5'UTR CoV-tar-miRNAs, i.e., hsa-miR-1303, hsa-miR-298, and hsa-miR-4645-3p. AGT gene encodes for the secretory preangiotensinogen or angiotensinogen precursor, which is essential for the renin-angiotensin system to maintain the blood pressure and fluid and electrolyte homeostasis in the body [43, 44].

Our study suggests that after SARS-CoV-2 infection, these genes associated with Diabetes and cell death get upregulated due to differential miRNA targeting and lead the pancreas cells to death. This hypothesis can be applied to the insulin-producing pancreas beta cells, 
resulting in low or no insulin secretion. This can worsen the condition of COVID-19 patients due to diabetic complications or new onset of Diabetes, even if the pancreas cell's miRNAs block the viral genome function. The mechanism of differential miRNA targeting must be further validated in vitro. For therapeutic purposes, artificial miRNAs can be designed and inserted into the infected cells to bind with the viral genome, thus, blocking both its function as well as the differential targeting of the host cell's miRNAs. A research study with this concept has been done with four artificial miRNAs for targeting and blocking the Chikungunya virus genome [45].

\section{Conclusion}

This study suggests that in a SARS-CoV-2-infected human pancreas cell, the native miRNAs target the viral genome instead of the cell's mRNAs that were being targeted before the infection. This differential miRNA targeting causes the pancreas cell's genes associated with Diabetes to upregulate, leading to diabetic complications or even new onset of Diabetes. Preventive, therapeutic methods are needed to block the viral genome from binding the host cell's miRNAs and facilitate binding with the externally provided artificial miRNAs.

\section{Acknowledgement}

B is supported with a Junior Research Fellowship from the Indian Council of Medical Research (ICMR), Govt. of India, New Delhi.

\section{Conflict of Interest}

The authors declare that there are no conflicts of interest with the contents of this article. 


\section{References}

1. WHO Director-General's opening remarks at the media briefing on COVID19 - March 2020.

2. World Health Organization (2020) Naming the coronavirus disease (COVID-19) and the virus that causes it.

3. WHO Coronavirus Disease (COVID-19) Dashboard. URL: covid19.who.int.

4. Chen, N., Zhou, M., Dong, X., Qu, J., Gong, F., Han, Y., Qiu, Y., Wang, J., Liu, Y. \& Wei, Y. (2020) Epidemiological and clinical characteristics of 99 cases of 2019 novel coronavirus pneumonia in Wuhan, China: a descriptive study, The lancet. 395, 507-513.

5. Lim, S., Bae, J. H., Kwon, H.-S. \& Nauck, M. A. (2020) COVID-19 and diabetes mellitus: from pathophysiology to clinical management, Nature Reviews Endocrinology, 1-20.

6. Modrow, S., Falke, D., Truyen, U. \& Schätzl, H. (2013) Viruses with single-stranded, positive-sense RNA genomes, Molecular virology, 185.

7. Codo, A. C., Davanzo, G. G., de Brito Monteiro, L., de Souza, G. F., Muraro, S. P., Virgilio-da-Silva, J. V., Prodonoff, J. S., Carregari, V. C., de Biagi Junior, C. A. O. \& Crunfli, F. (2020) Elevated glucose levels favor SARS-CoV-2 infection and monocyte response through a HIF-1 $\alpha /$ glycolysis-dependent axis, Cell metabolism. 32, 437-446. e5.

8. Rubino, F., Amiel, S. A., Zimmet, P., Alberti, G., Bornstein, S., Eckel, R. H., Mingrone, G., Boehm, B., Cooper, M. E. \& Chai, Z. (2020) New-onset diabetes in Covid-19, New England Journal of Medicine. 383, 789-790.

9. Chee, Y. J., Ng, S. J. H. \& Yeoh, E. (2020) Diabetic ketoacidosis precipitated by Covid-19 in a patient with newly diagnosed diabetes mellitus, Diabetes research and clinical practice.

10. Ren, H., Yang, Y., Wang, F., Yan, Y., Shi, X., Dong, K., Yu, X. \& Zhang, S. (2020) Association of the insulin resistance marker TyG index with the severity and mortality of COVID-19, Cardiovascular diabetology. 19, 1-8.

11. Diabetes, T. L. (2020) COVID-19 and Diabetes: a co-conspiracy?, The Lancet Diabetes \& Endocrinology. 8, 801 .

12. Yao, X., Li, T., He, Z., Ping, Y., Liu, H., Yu, S., Mou, H., Wang, L., Zhang, H. \& Fu, W. (2020) A pathological report of three COVID-19 cases by minimally invasive autopsies, Zhonghua bing li xue za zhi= Chinese journal of pathology. 49, E009-E009.

13. Walls, A. C., Park, Y.-J., Tortorici, M. A., Wall, A., McGuire, A. T. \& Veesler, D. (2020) Structure, function, and antigenicity of the SARS-CoV-2 spike glycoprotein, Cell. 181, 281-292. e6. 
14. Yang, J.-K., Lin, S.-S., Ji, X.-J. \& Guo, L.-M. (2010) Binding of SARS coronavirus to its receptor damages islets and causes acute Diabetes, Acta diabetologica. 47, 193-199.

15. Girardi, E., López, P. \& Pfeffer, S. (2018) On the importance of host microRNAs during viral infection, Frontiers in genetics. 9, 439.

16. Guterres, A., de Azeredo Lima, C. H., Miranda, R. L. \& Gadelha, M. R. (2020) What is the potential function of microRNAs as biomarkers and therapeutic targets in COVID-19?, Infection, Genetics and Evolution. 85, 104417.

17. Trobaugh, D. W., Gardner, C. L., Sun, C., Haddow, A. D., Wang, E., Chapnik, E., Mildner, A., Weaver, S. C., Ryman, K. D. \& Klimstra, W. B. (2014) RNA viruses can hijack vertebrate microRNAs to suppress innate immunity, Nature. 506, 245-248.

18. Zheng, Z., Ke, X., Wang, M., He, S., Li, Q., Zheng, C., Zhang, Z., Liu, Y. \& Wang, H. (2013) Human microRNA hsa-miR-296-5p suppresses enterovirus 71 replication by targeting the viral genome, Journal of virology. 87, 5645-5656.

19. Yang, L., Han, Y., Nilsson-Payant, B. E., Gupta, V., Wang, P., Duan, X., Tang, X., Zhu, J., Zhao, Z. \& Jaffré, F. (2020) A human pluripotent stem cell-based platform to study SARSCoV-2 tropism and model virus infection in human cells and organoids, Cell stem cell. 27, 125-136. e7.

20. Love, M. I., Huber, W. \& Anders, S. (2014) Moderated estimation of fold change and dispersion for RNA-seq data with DESeq2, Genome biology. 15, 1-21.

21. Zhu, A., Ibrahim, J. G. \& Love, M. I. (2019) Heavy-tailed prior distributions for sequence count data: removing the noise and preserving large differences, Bioinformatics. 35, 2084-2092.

22. Becker, K. G., Barnes, K. C., Bright, T. J. \& Wang, S. A. (2004) The genetic association database, Nature genetics. 36, 431-432.

23. Huang, D. W., Sherman, B. T. \& Lempicki, R. A. (2009) Bioinformatics enrichment tools: paths toward the comprehensive functional analysis of large gene lists, Nucleic acids research. 37, 1-13.

24. Montojo, J., Zuberi, K., Rodriguez, H., Bader, G. D. \& Morris, Q. (2014) GeneMANIA: Fast gene network construction and function prediction for Cytoscape, F1000Research. 3.

25. Shannon, P., Markiel, A., Ozier, O., Baliga, N. S., Wang, J. T., Ramage, D., Amin, N., Schwikowski, B. \& Ideker, T. (2003) Cytoscape: a software environment for integrated models of biomolecular interaction networks, Genome research. 13, 2498-2504.

26. Warde-Farley, D., Donaldson, S. L., Comes, O., Zuberi, K., Badrawi, R., Chao, P., Franz, M., Grouios, C., Kazi, F. \& Lopes, C. T. (2010) The GeneMANIA prediction server: 
biological network integration for gene prioritization and predicting gene function, Nucleic acids research. 38, W214-W220.

27. Assenov, Y., Ramírez, F., Schelhorn, S.-E., Lengauer, T. \& Albrecht, M. (2008) Computing topological parameters of biological networks, Bioinformatics. 24, 282-284.

28. Wu, F., Zhao, S., Yu, B., Chen, Y.-M., Wang, W., Song, Z.-G., Hu, Y., Tao, Z.-W., Tian, J.-H. \& Pei, Y.-Y. (2020) A new coronavirus associated with human respiratory disease in China, Nature. 579, 265-269.

29. Chen, Y. \& Wang, X. (2020) miRDB: an online database for prediction of functional microRNA targets, Nucleic acids research. 48, D127-D131.

30. Liu, W. \& Wang, X. (2019) Prediction of functional microRNA targets by integrative modeling of microRNA binding and target expression data, Genome biology. 20, 1-10.

31. Dweep, H. \& Gretz, N. (2015) miRWalk2. 0: a comprehensive atlas of microRNA-target interactions, Nature methods. 12, 697-697.

32. Dweep, H., Sticht, C., Pandey, P. \& Gretz, N. (2011) miRWalk-database: prediction of possible miRNA binding sites by "walking" the genes of three genomes, Journal of biomedical informatics. 44, 839-847.

33. Ludwig, N., Leidinger, P., Becker, K., Backes, C., Fehlmann, T., Pallasch, C., Rheinheimer, S., Meder, B., Stähler, C. \& Meese, E. (2016) Distribution of miRNA expression across human tissues, Nucleic acids research. 44, 3865-3877.

34. Molitch, M. E., DeFronzo, R. A., Franz, M. J. \& Keane, W. F. (2004) Nephropathy in Diabetes, Diabetes care. 27, S79.

35. Pemp, B. \& Schmetterer, L. (2008) Ocular blood flow in Diabetes and age-related macular degeneration, Canadian journal of ophthalmology. 43, 295-301.

36. Topouzis, F., Anastasopoulos, E., Augood, C., Bentham, G. C., Chakravarthy, U., de Jong, P. T., Rahu, M., Seland, J., Soubrane, G. \& Tomazzoli, L. (2009) Association of Diabetes with age-related macular degeneration in the EUREYE study, British journal of ophthalmology. 93, 1037-1041.

37. Kamura, T., Maenaka, K., Kotoshiba, S., Matsumoto, M., Kohda, D., Conaway, R. C., Conaway, J. W. \& Nakayama, K. I. (2004) VHL-box and SOCS-box domains determine binding specificity for Cul2-Rbx1 and Cul5-Rbx2 modules of ubiquitin ligases, Genes \& development. 18, 3055-3065.

38. Mori, H., Shichita, T., Yu, Q., Yoshida, R., Hashimoto, M., Okamoto, F., Torisu, T., Nakaya, M., Kobayashi, T. \& Takaesu, G. (2007) Suppression of SOCS3 expression in the 
pancreatic $\beta$-cell leads to resistance to type 1 diabetes, Biochemical and biophysical research communications. 359, 952-958.

39. Jean-Baptiste, V. S., Xia, C.-Q., Clare-Salzler, M. J. \& Horwitz, M. S. (2017) Type 1 diabetes and type 1 interferonopathies: localization of a type 1 common thread of virus infection in the pancreas, EBioMedicine. 22, 10-17.

40. Yang, Z., Gagarin, D., St. Laurent III, G., Hammell, N., Toma, I., Hu, C.-a., Iwasa, A. \& McCaffrey, T. A. (2009) Cardiovascular inflammation and lesion cell apoptosis: a novel connection via the interferon-inducible immunoproteasome, Arteriosclerosis, thrombosis, and vascular biology. 29, 1213-1219.

41. Cunninghamn, J., Leffell, M., Mearkle, P. \& Harmatz, P. (1995) Elevated plasma ceruloplasmin in insulin-dependent diabetes mellitus: evidence for increased oxidative stress as a variable complication, Metabolism. 44, 996-999.

42. Moreno-Navarrete, J. M., Martínez-Barricarte, R., Catalán, V., Sabater, M., GómezAmbrosi, J., Ortega, F. J., Ricart, W., Blüher, M., Frühbeck, G. \& de Cordoba, S. R. (2010) Complement factor $\mathrm{H}$ is expressed in adipose tissue in association with insulin resistance, Diabetes. 59, 200-209.

43. Goodfriend, T. L. \& Peach, M. J. (1975) Angiotensin III:(DES-aspartic acid-1)angiotensin II. Evidence and speculation for its role as an important agonist in the reninangiotensin system, Circulation Research. 36, 38-48.

44. Weir, M. R. \& Dzau, V. J. (1999) The renin-angiotensin-aldosterone system: a specific target for hypertension management, American journal of hypertension. 12, 205S-213S.

45. Saha, A., Bhagyawant, S. S., Parida, M. \& Dash, P. K. (2016) Vector-delivered artificial miRNA effectively inhibited replication of Chikungunya virus, Antiviral research. 134, 4249. 


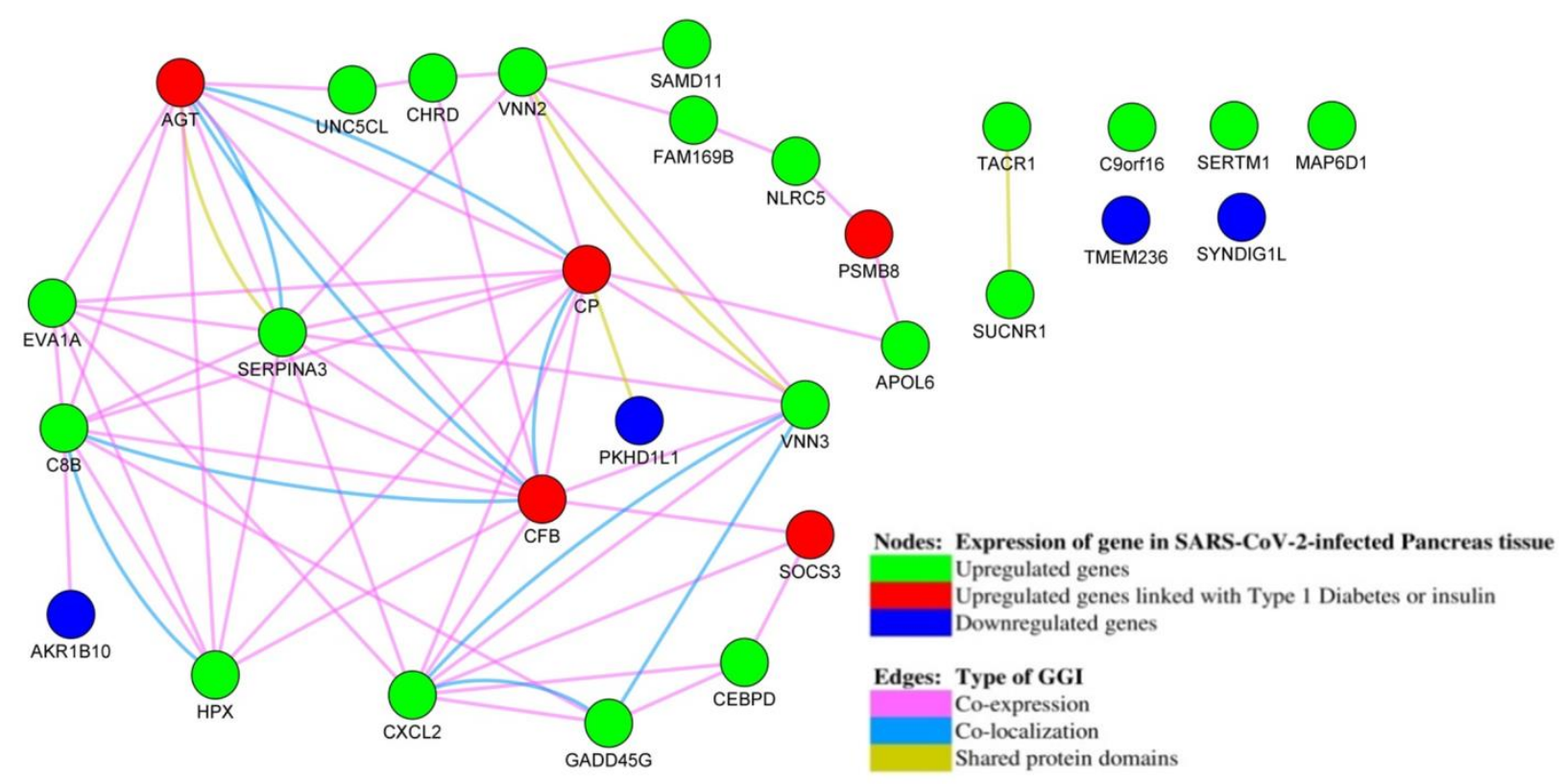

Figure 1. GeneMANIA gene-gene interaction network between the Differentially expressed genes 


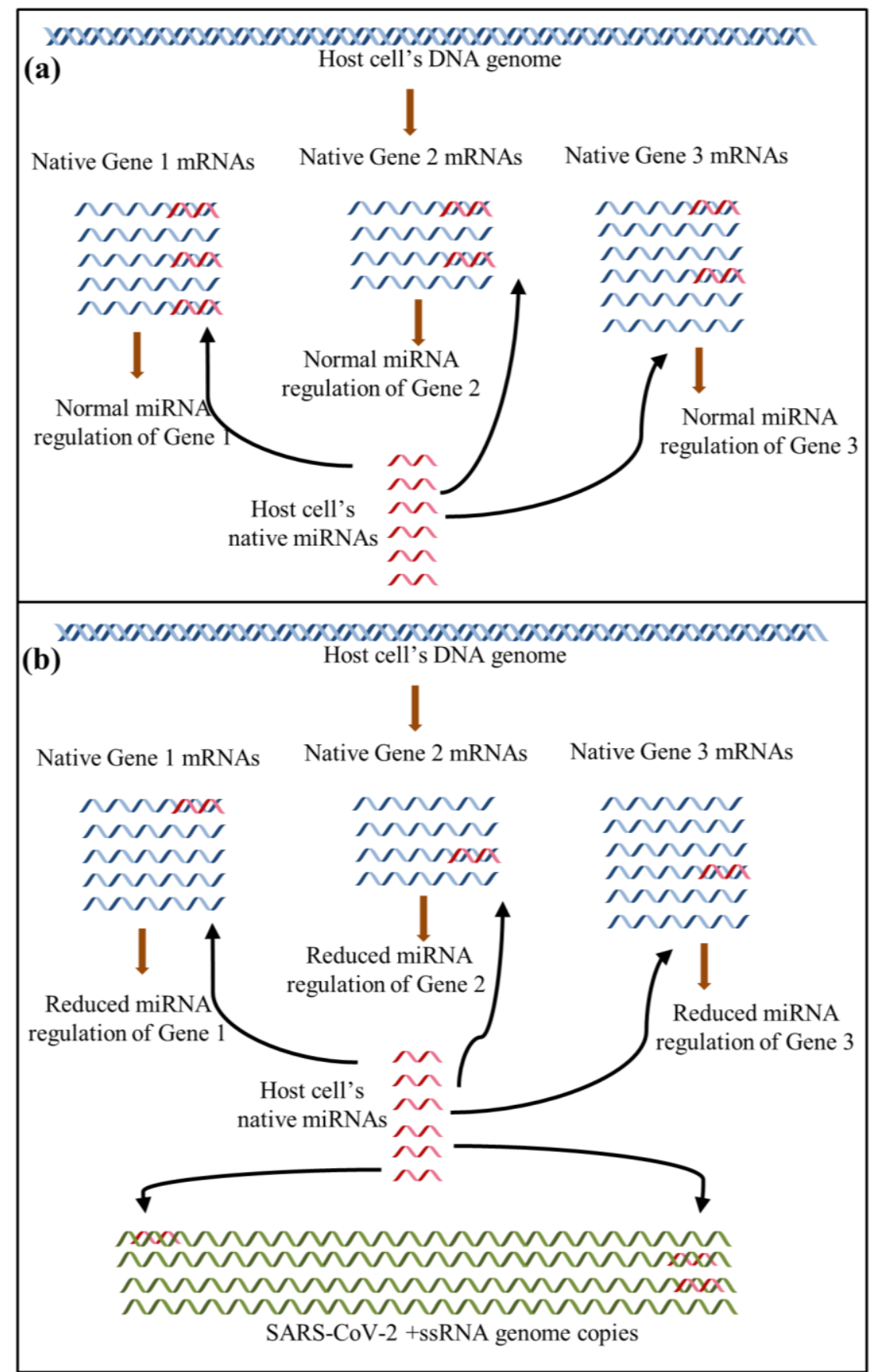

Figure 2. Differential targeting of the host cell's native miRNAs (a) The cell's native miRNAs regulate the genes by targeting and suppressing the cell's native mRNAs only. (b) In a SARS-CoV-2infected cell, the viral +ssRNA genome copies compete with the host cell's native mRNAs in being targeted by the native miRNAs. The native miRNAs get apportioned in targeting the SARS-CoV-2 genome copies too. It reduces the contribution of miRNAs in regulating the native cell's genes, thus, upregulating them. 


\section{Tables}

Table 1: Differentially Expressed Genes in SARS-CoV-2-infected hESC pancreas tissue

\begin{tabular}{|c|c|c|c|c|c|}
\hline S. No. & Gene Symbol & Log2FoldChange & S. No. & Gene Symbol & Log2FoldChange \\
\hline 1. & CP & 3.218646021 & 16. & CHRD & 1.226960717 \\
\hline 2. & SOCS3 & 2.897737916 & 17. & GADD45G & 1.223936929 \\
\hline 3. & VNN3 & 2.676974204 & 18. & APOL6 & 1.164596924 \\
\hline 4. & CEBPD & 2.041519486 & 19. & SAMD11 & 1.129551911 \\
\hline 5. & FAM169B & 1.887720767 & 20. & AGT & 1.106392771 \\
\hline 6. & VNN2 & 1.650151224 & 21. & C9orf16 & 1.096117015 \\
\hline 7. & HPX & 1.576405664 & 22. & NLRC5 & 1.094272111 \\
\hline 8. & EVA1A & 1.483037767 & 23. & SUCNR1 & 1.067266654 \\
\hline 9. & SERTM1 & 1.482242018 & 24. & PSMB8 & 1.031089013 \\
\hline 10. & CXCL2 & 1.464664038 & 25. & UNC5CL & 1.015471709 \\
\hline 11. & C8B & 1.45102627 & 26. & MAP6D1 & 1.000047502 \\
\hline 12. & CFB & 1.449773368 & 27. & AKR1B10* & -1.942847572 \\
\hline 13. & SERPINA3 & 1.282619509 & 28. & SYNDIG1L* & -1.628255609 \\
\hline 14. & TACR1 & 1.253706268 & 29. & PKHD1L1* & -1.414217069 \\
\hline 15. & HCP5 & 1.228387286 & 30. & TMEM236* & -1.040226661 \\
\hline
\end{tabular}

*Genes downregulated in SARS-CoV-2-infected hESC pancreas tissue.

Table 2: Gene-based GAD disease enrichment of DEGs

\begin{tabular}{|c|c|c|}
\hline S. No. & Disease Term & Genes \\
\hline 1. & Type 1 Diabetes & $\mathrm{SOCS}, \mathrm{AGT}^{\mathrm{S}}, \mathrm{CP}^{\mathrm{S}}, \mathrm{PSMB} 8$ \\
\hline 2. & $\begin{array}{l}\text { Alzheimer's Disease, Parkinson's Disease, } \\
\text { Insulin, Lung Function, Depression, } \\
\text { Longevity }\end{array}$ & $\mathrm{CFB}^{\mathrm{S}}, \mathrm{CP}^{\mathrm{S}}$ \\
\hline 3. & Cerebrovascular Disease & AGT $^{\mathrm{S}}, \mathrm{SERPINA3}^{\mathrm{S}}$ \\
\hline 4. & $\begin{array}{l}\text { Respiratory Syncytial Virus Bronchiolitis, } \\
\text { Asthma, Bronchiolitis }\end{array}$ & SOCS3, CXCL2 ${ }^{\mathrm{S}}$, PSMB8 \\
\hline 5. & $\begin{array}{l}\text { Birth Weight, Leukemia, Acute Myeloid } \\
\text { Leukemia, Precursor Cell Lymphoblastic } \\
\text { Leukemia-Lymphoma, Meningeal Neoplasms, } \\
\text { Meningioma, Non-Hodgkin's Lymphoma }\end{array}$ & $\mathrm{C} 8 \mathrm{~B}^{\mathrm{S}}, \mathrm{SOCS} 3, \mathrm{CFB}^{\mathrm{S}}$ \\
\hline 6. & Nephropathy & $\mathrm{AGT}^{\mathrm{S}}, \mathrm{AKR} 1 \mathrm{~B} 10^{\mathrm{S}}$ \\
\hline 7. & Myocardial Infarction & EVA1A, AGT $^{S}$, GADD45G, SERPINA3 ${ }^{S}$ \\
\hline 8. & Plasma HDL Cholesterol (HDL-C) Levels & SOCS3, CEBPD, AGT $^{\mathrm{S}}$ \\
\hline 9. & Macular Degeneration &  \\
\hline
\end{tabular}

${ }^{\mathrm{s}}$ Genes encoding for secretory proteins. 
Table 3: GeneMANIA GGI between the Diabetes-associated DEGs

\begin{tabular}{|c|c|c|c|c|}
\hline S.No. & $\begin{array}{c}\text { Diabetes- } \\
\text { associated } \\
\text { gene } \\
\text { nodes }\end{array}$ & $\begin{array}{l}\text { Diabetes- } \\
\text { associated } \\
\text { interacting } \\
\text { gene nodes }\end{array}$ & Direct/Indirect GGI & Type of GGI \\
\hline 1. & $\mathrm{CP}$ & $\begin{array}{c}\text { AGT } \\
\text { CFB } \\
\text { SOCS3 } \\
\text { PSMB8 }\end{array}$ & $\begin{array}{c}\text { Direct } \\
\text { Direct } \\
\text { Indirect -Through CFB } \\
\text { Indirect -Through APOL6 }\end{array}$ & $\begin{array}{c}\text { Co-expression, Co-localization } \\
\text { Co-expression, Co-localization } \\
\text { Co-expression* } \\
\text { Co-expression* }\end{array}$ \\
\hline 2. & SOCS3 & $\begin{array}{c}\text { CFB } \\
\text { AGT } \\
\text { PSMB8 }\end{array}$ & $\begin{array}{c}\text { Direct } \\
\text { Indirect -Through CFB } \\
\text { Indirect -Through CFB-CP- } \\
\text { APOL6 }\end{array}$ & $\begin{array}{l}\text { Co-expression* } \\
\text { Co-expression* } \\
\text { Co-expression* }\end{array}$ \\
\hline 3. & AGT & $\begin{array}{c}\text { CFB } \\
\text { PSMB8 }\end{array}$ & $\begin{array}{c}\text { Direct } \\
\text { Indirect -Through CP-APOL6 }\end{array}$ & $\begin{array}{c}\text { Co-expression, Co-localization } \\
\text { Co-expression* }\end{array}$ \\
\hline 4. & PSMB8 & CFB & Indirect -Through CP & Co-expression* \\
\hline
\end{tabular}

*Indirect interaction through more than one co-expression edge.

Table 4: GeneMANIA direct GGI between the upregulated and downregulated DEGs

\begin{tabular}{|r|c|c|c|c|}
\hline S.No. & Downregulated gene & Upregulated gene & Direct/Indirect GGI & Type of GGI \\
\hline 1. & AKR1B10 & C8B & Direct & Co-expression \\
\hline 2. & PKHD1L1 & CP & Direct & Shared protein domains \\
\hline 3. & SYNDIG1L & None & - & - \\
\hline 4. & TMEM236 & None & - & - \\
\hline
\end{tabular}


Table 5: Topological parameters of the GGI network (in descending order of Closeness

Centrality)

\begin{tabular}{|c|c|c|c|c|}
\hline S. No. & Gene name & Degree & Closeness Centrality & Betweenness Centrality \\
\hline 1. & SUCNR1 & 1 & 1 & 0 \\
\hline 2. & TACR1 & 1 & 1 & 0 \\
\hline 3. & $\mathrm{CP}^{\mathrm{D}}$ & 11 & 0.65625 & 0.334650416 \\
\hline 4. & SERPINA3 & 9 & 0.6 & 0.078909675 \\
\hline 5. & $\mathrm{CFB}^{\mathrm{D}}$ & 10 & 0.567567568 & 0.124459562 \\
\hline 6. & $\mathrm{C} 8 \mathrm{~B}$ & 8 & 0.538461538 & 0.124801587 \\
\hline 7. & EVA1A & 7 & 0.525 & 0.007420635 \\
\hline 8. & VNN3 & 6 & 0.525 & 0.055616024 \\
\hline 9. & VNN2 & 6 & 0.525 & 0.25037037 \\
\hline 10. & $\mathrm{AGT}^{\mathrm{D}}$ & 7 & 0.512195122 & 0.062619048 \\
\hline 11. & CXCL2 & 8 & 0.512195122 & 0.101135676 \\
\hline 12. & HPX & 6 & 0.5 & 0 \\
\hline 13. & CHRD & 3 & 0.446808511 & 0.034950869 \\
\hline 14. & APOL6 & 2 & 0.4375 & 0.096216931 \\
\hline 15. & GADD45G & 4 & 0.4375 & 0.022896825 \\
\hline 16. & PKHD1L1 & 1 & 0.403846154 & 0 \\
\hline 17. & $\mathrm{SOCS}^{\mathrm{D}}$ & 3 & 0.396226415 & 0.007539683 \\
\hline 18. & UNC5CL & 2 & 0.381818182 & 0.002380952 \\
\hline 19. & FAM169B & 2 & 0.375 & 0.07521164 \\
\hline 20. & CEBPD & 3 & 0.368421053 & 0.002380952 \\
\hline 21. & AKR1B10 & 1 & 0.355932203 & 0 \\
\hline 22. & SAMD11 & 1 & 0.35 & 0 \\
\hline 23. & $\mathrm{PSMB}^{\mathrm{D}}$ & 2 & 0.328125 & 0.023994709 \\
\hline 24. & NLRC5 & 2 & 0.291666667 & 0.013492063 \\
\hline 25. & C9orf16* & 0 & 0 & 0 \\
\hline 26. & TMEM236* & 0 & 0 & 0 \\
\hline 27. & SYNDIG1L* & 0 & 0 & 0 \\
\hline 28. & SERTM1* & 0 & 0 & 0 \\
\hline 29. & MAP6D1* & 0 & 0 & 0 \\
\hline
\end{tabular}

*Single node in the network.

${ }^{\mathrm{D}}$ Differentially Expressed Genes associated with Diabetes. 
Table 6: Potential miRNAs targeting the 3'UTR of the viral genome (CoV-tar-miRNAs)

\begin{tabular}{|c|c|c|c|}
\hline S. No. & miRNA Name and its sequence & $\begin{array}{l}\text { Seed Location on the } \\
\text { viral 3'UTR sequence }\end{array}$ & The target sequence of miRNAs \\
\hline 1. & $\begin{array}{c}\text { hsa-miR-3941 } \\
\text { UUACACACAACUGAGGAUCAUA }\end{array}$ & 14,133 & $\begin{array}{l}\text { CAATCTTTAATCAGTGTGTAACATTAGGGAGGACTTGAAAGAGCCACCACATTTTCACCGAGGCCACGCG } \\
\text { GAGTACGATCGAGTGTACAGTGAACAATGCTAGGGAGAGCTGCCTATATGGAAGAGCCCTAATGTGTAAA } \\
\text { ATTAATTTTAGTAGTGCTATCCCCATGTGATTTTAATAGCTTCTTAGGAGAATGACAAAAAAAAAAAAAA } \\
\text { AAAAAAAAAAAAAAAAAAA }\end{array}$ \\
\hline 2. & $\begin{array}{c}\text { hsa-miR-466 } \\
\text { AUACACAUACACGCAACACACAU }\end{array}$ & 15,132 & $\begin{array}{l}\text { CAATCTTTAATCAGTGTGTAACATTAGGGAGGACTTGAAAGAGCCACCACATTTTCACCGAGGCCACGCG } \\
\text { GAGTACGATCGAGTGTACAGTGAACAATGCTAGGGAGAGCTGCCTATATGGAAGAGCCCTAATGTGTAAA } \\
\text { ATTAATTTAGTAGTGCTATCCCCATGTGATTTTAATAGCTTCTTAGGAGAATGACAAAAAAAAAAAAAA } \\
\text { AAAAAAAAAAAAAAAAAAA }\end{array}$ \\
\hline 3. & $\begin{array}{c}\text { hsa-miR-4775 } \\
\text { UUAAUUUUUUGUUUCGGUCACU }\end{array}$ & 138 & $\begin{array}{l}\text { CAATCTTTAATCAGTGTGTAACATTAGGGAGGACTTGAAAGAGCCACCACATTTTCACCGAGGCCACGCG } \\
\text { GAGTACGATCGAGTGTACAGTGACAATGCTAGGGAGAGCTGCCTATATGGAAGAGCCCTAATGTGTAAA } \\
\text { ATTAATTTTAGTAGTGCTATCCCCATGTGATTTTAATAGCTTCTTAGGAGAATGACAAAAAAAAAAAAAA } \\
\text { AAAAAAAAAAAAAAAAAAA }\end{array}$ \\
\hline 4. & $\begin{array}{c}\text { hsa-miR-4717-3p } \\
\text { ACACAUGGGUGGCUGUGGCCU }\end{array}$ & 163 & $\begin{array}{l}\text { CAATCTTTAATCAGTGTGTAACATTAGGGAGGACTTGAAAGAGCCACCACATTTTCACCGAGGCCACGCG } \\
\text { GAGTACGATCGAGTGTACAGTGAACAATGCTAGGGAGAGCTGCCTATATGGAAGAGCCCTAATGTGTAAA } \\
\text { ATTAATTTTAGTAGTGCTATCCCCATGTGATTTTAATAGCTTCTTAGGAGAATGACAAAAAAAAAAAAAA } \\
\text { AAAAAAAAAAAAAAAAAAA }\end{array}$ \\
\hline 5. & $\begin{array}{c}\text { hsa-miR-5088-5p } \\
\text { CAGGGCUCAGGGAUUGGAUGGAGG }\end{array}$ & 124 & $\begin{array}{l}\text { CAATCTTTAATCAGTGTGTAACATTAGGGAGGACTTGAAAGAGCCACCACATTTTCACCGAGGCCACGCG } \\
\text { GAGTACGATCGAGTGTACAGTGAACAATGCTAGGGAGAGCTGCCTATATGGAAGAGCCCTAATGTGTAAA } \\
\text { ATTAATTTAGTAGTGCTATCCCCATGTGATTTTAATAGCTTCTTAGGAGAATGACAAAAAAAAAAAAAA } \\
\text { AAAAAAAAAAAAAAAAAAA }\end{array}$ \\
\hline 6. & $\begin{array}{c}\text { hsa-miR-603 } \\
\text { CACACACUGCAAUUACUUUUGC }\end{array}$ & 13 & $\begin{array}{l}\text { CAATCTTTAATCAGTGTGTAACATTAGGGAGGACTTGAAAGAGCCACCACATTTTCACCGAGGCCACGCG } \\
\text { GAGTACGATCGAGTGTACAGTGAACAATGCTAGGGAGAGCTGCCTATATGGAAGAGCCCTAATGTGTAAA } \\
\text { ATTAATTTTAGTAGTGCTATCCCCATGTGATTTTAATAGCTTCTTAGGAGAATGACAAAAAAAAAAAAAA } \\
\text { AAAAAAAAAAAAAAAAAAA }\end{array}$ \\
\hline 7. & $\begin{array}{c}\text { hsa-miR-6749-3p } \\
\text { CUCCUCCCCUGCCUGGCCCAG }\end{array}$ & 27 & $\begin{array}{l}\text { CAATCTTTAATCAGTGTGTAACATTAGGGAGGACTTGAAAGAGCCACCACATTTTCACCGAGGCCACGCG } \\
\text { GAGTACGATCGAGTGTACAGTGAACAATGCTAGGGAGAGCTGCCTATATGGAAGAGCCCTAATGTGTAAA } \\
\text { ATTAATTTTAGTAGTGCTATCCCCATGTGATTTTAATAGCTTCTTAGGAGAATGACAAAAAAAAAAAAAA } \\
\text { AAAAAAAAAAAAAAAAAAA }\end{array}$ \\
\hline 8. & $\begin{array}{c}\text { hsa-miR-1236-3p } \\
\text { CCUCUUCCCCUUGUCUCUCCAG }\end{array}$ & 120 & $\begin{array}{l}\text { CAATCTTTAATCAGTGTGTAACATTAGGGAGGACTTGAAAGAGCCACCACATTTTCACCGAGGCCACGCG } \\
\text { GAGTACGATCGAGTGTACAGTGAACAATGCTAGGGAGAGCTGCCTATATGGAAGAGCCCTAATGTGTAAA } \\
\text { ATTAATTTTAGTAGTGCTATCCCCATGTGATTTTAATAGCTTCTTAGGAGAATGACAAAAAAAAAAAAAA } \\
\text { AAAAAAAAAAAAAAAAAAA }\end{array}$ \\
\hline 9. & $\begin{array}{c}\text { hsa-miR-4279 } \\
\text { CUCUCCUCCCGGCUUC }\end{array}$ & 186 & $\begin{array}{l}\text { CAATCTTTAATCAGTGTGTAACATTAGGGAGGACTTGAAAGAGCCACCACATTTTCACCGAGGCCACGCG } \\
\text { GAGTACGATCGAGTGTACAGTGAACAATGCTAGGGAGAGCTGCCTATATGGAAGAGCCCTAATGTGTAAA } \\
\text { ATTAATTTTAGTAGTGCTATCCCCATGTGATTTTAATAGCTTCTTAGGAGAATGACAAAAAAAAAAAAAA } \\
\text { AAAAAAAAAAAAAAAAAAA }\end{array}$ \\
\hline 10. & $\begin{array}{c}\text { hsa-miR-4672 } \\
\text { UUACACAGCUGGACAGAGGCA }\end{array}$ & 15,133 & $\begin{array}{l}\text { CAATCTTTAATCAGTGTGTAACATTAGGGAGGACTTGAAAGAGCCACCACATTTTCACCGAGGCCACGCG } \\
\text { GAGTACGATCGAGTGTACAGTGAACAATGCTAGGGAGAGCTGCCTATATGGAAGAGCCCTAATGTGTAAA } \\
\text { ATTAATTTTAGTAGTGCTATCCCCATGTGATTTTAATAGCTTCTTAGGAGAATGACAAAAAAAAAAAAAA } \\
\text { AAAAAAAAAAAAAAAAAAA }\end{array}$ \\
\hline
\end{tabular}


Table 7: Potential miRNAs targeting the 5'UTR of the viral genome (CoV-tar-miRNAs)

\begin{tabular}{|c|c|c|c|}
\hline S. No. & miRNA Name and its sequence & $\begin{array}{l}\text { Seed Location on } \\
\text { the viral 5'UTR } \\
\text { sequence }\end{array}$ & The target sequence of miRNAs \\
\hline 1. & $\begin{array}{c}\text { hsa-miR-298 } \\
\text { AGCAGAAGCAGGGAGGUUCUCCCA }\end{array}$ & 180 & $\begin{array}{l}\text { ATTAAAGGTTTATACCTTCCCAGGTAACAAACCAACCAACTTTCGATCTCTTGTAGATCTGTTCTCTAAA } \\
\text { CGAACTTTAAAATCTGTGTGGCTGTCACTCGGCTGCATGCTTAGTGCACTCACGCAGTATAATTAATACA } \\
\text { TAATTACTGTCGTTGACAGGACACGAGTAACTCGTCTATCTTCTGCAGGCTGCTTACGGTTTCGTCCGTG } \\
\text { TTGCAGCCGATCATCAGCACATCTAGGTTTCGTCCGGGTGTGACCGAAAGGTAAG }\end{array}$ \\
\hline 2. & $\begin{array}{c}\text { hsa-miR-7851-3p } \\
\text { UACCUGGGAGACUGAGGUUGGA }\end{array}$ & 19 & $\begin{array}{l}\text { ATTAAAGGTTTATACCTTCCCAGGTAACAAACCAACCAACTTTCGATCTCTTGTAGATCTGTTCTCTAAA } \\
\text { CGAACTTTAAAATCTGTGTGGCTGTCACTCGGCTGCATGCTTAGTGCACTCACGCAGTATAATTAATAC } \\
\text { TAATTACTGTCGTTGACAGGACACGAGTAACTCGTCTATCTTCTGCAGGCTGCTTACGGTTTCGTCCGTG } \\
\text { TTGCAGCCGATCATCAGCACATCTAGGTTTCGTCCGGGTGTGACCGAAAGGTAAG }\end{array}$ \\
\hline 3. & $\begin{array}{c}\text { hsa-miR-1303 } \\
\text { UUUAGAGACGGGGUCUUGCUCU }\end{array}$ & 63 & $\begin{array}{l}\text { ATTAAAGGTTTATACCTTCCCAGGTAACAAACCAACCAACTTTCGATCTCTTGTAGATCTGTTCTCTAAA } \\
\text { CGAACTTTAAAATCTGTGTGGCTGTCACTCGGCTGCATGCTTAGTGCACTCACGCAGTATAATTAATAC } \\
\text { TAATTACTGTCGTTGACAGGACACGAGTAACTCGTCTATCTTCTGCAGGCTGCTTACGGTTTCGTCCGTG } \\
\text { TTGCAGCCGATCATCAGCACATCTAGGTTTCGTCCGGGTGTGACCGAAAGGTAAG }\end{array}$ \\
\hline 4. & $\begin{array}{c}\text { hsa-miR-3925-5p } \\
\text { AAGAGAACUGAAAGUGGAGCCU }\end{array}$ & 61 & $\begin{array}{l}\text { ATTAAAGGTTTATACCTTCCCAGGTAACAAACCAACCAACTTTCGATCTCTTGTAGATCTGTTCTCTAAA } \\
\text { CGAACTTTAAAATCTGTGTGGCTGTCACTCGGCTGCATGCTTAGTGCACTCACGCAGTATAATTAATAC } \\
\text { TAATTACTGTCGTTGACAGGACACGAGTAACTCGTCTATCTTCTGCAGGCTGCTTACGGTTTCGTCCGTG } \\
\text { TTGCAGCCGATCATCAGCACATCTAGGTTTCGTCCGGGTGTGACCGAAAGGTAAG }\end{array}$ \\
\hline 5. & $\begin{array}{c}\text { hsa-miR-8075 } \\
\text { UGCUGAUGGCAGAUGUCGGGUCUG }\end{array}$ & 222 & 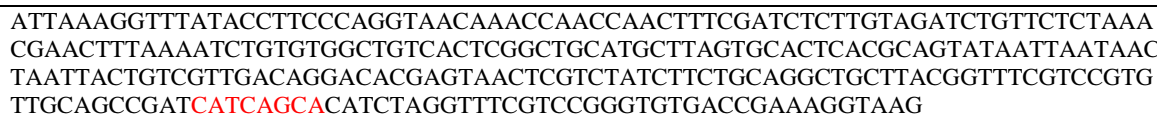 \\
\hline 6. & $\begin{array}{c}\text { hsa-miR-4691-3p } \\
\text { CCAGCCACGGACUGAGAGUGCAU }\end{array}$ & 88 & $\begin{array}{l}\text { ATTAAAGGTTTATACCTTCCCAGGTAACAAACCAACCAACTTTCGATCTCTTGTAGATCTGTTCTCTAAA } \\
\text { CGAACTTTAAAATCTGTGTGGCTGTCACTCGGCTGCATGCTTAGTGCACTCACGCAGTATAATTAATAC } \\
\text { TAATTACTGTCGTTGACAGGACACGAGTAACTCGTCTATCTTCTGCAGGCTGCTTACGGTTTCGTCCGTG } \\
\text { TTGCAGCCGATCATCAGCACATCTAGGTTTCGTCCGGGTGTGACCGAAAGGTAAG }\end{array}$ \\
\hline 7. & $\begin{array}{c}\text { hsa-miR-1283 } \\
\text { UCUACAAAGGAAAGCGCUUUCU }\end{array}$ & 51 & $\begin{array}{l}\text { ATTAAAGGTTTATACCTTCCCAGGTAACAAACCAACCAACTTTCGATCTCTTGTAGATCTGTTCTCTAAA } \\
\text { CGAACTTTAAAATCTGTGTGGCTGTCACTCGGCTGCATGCTTAGTGCACTCACGCAGTATAATTAATACA } \\
\text { TAATTACTGTCGTTGACAGGACACGAGTAACTCGTCTATCTTCTGCAGGCTGCTTACGGTTTCGTCCGTG } \\
\text { TTGCAGCCGATCATCAGCACATCTAGGTTTCGTCCGGGTGTGACCGAAAGGTAAG }\end{array}$ \\
\hline 8. & $\begin{array}{c}\text { hsa-miR-3123 } \\
\text { CAGAGAAUUGUUUAAUC }\end{array}$ & 62 & $\begin{array}{l}\text { ATTAAAGGTTTATACCTTCCCAGGTAACAAACCAACCAACTTTCGATCTCTTGTAGATCTGTTCTCTAAA } \\
\text { CGAACTTTAAAATCTGTGTGGCTGTCACTCGGCTGCATGCTTAGTGCACTCACGCAGTATAATTAATAC } \\
\text { TAATTACTGTCGTTGACAGGACACGAGTAACTCGTCTATCTTCTGCAGGCTGCTTACGGTTTCGTCCGTG } \\
\text { TTGCAGCCGATCATCAGCACATCTAGGTTTCGTCCGGGTGTGACCGAAAGGTAAG }\end{array}$ \\
\hline 9. & $\begin{array}{l}\text { hsa-miR-5196-5p } \\
\text { AGGGAAGGGGACGAGGGUUGGG }\end{array}$ & 15 & $\begin{array}{l}\text { ATTAAAGGTTTATACCTTCCCAGGTAACAAACCAACCAACTTTCGATCTCTTGTAGATCTGTTCTCTAAA } \\
\text { CGAACTTTAAAATCTGTGTGGCTGTCACTCGGCTGCATGCTTAGTGCACTCACGCAGTATAATTAATAC } \\
\text { TAATTACTGTCGTTGACAGGACACGAGTAACTCGTCTATCTTCTGCAGGCTGCTTACGGTTTCGTCCGTG } \\
\text { TTGCAGCCGATCATCAGCACATCTAGGTTTCGTCCGGGTGTGACCGAAAGGTAAG }\end{array}$ \\
\hline 10. & $\begin{array}{l}\text { hsa-miR-4747-5p } \\
\text { AGGGAAGGAGGCUUGGUCUUAG }\end{array}$ & 15 & $\begin{array}{l}\text { ATTAAAGGTTTATACCTTCCCAGGTAACAAACCAACCAACTTTCGATCTCTTGTAGATCTGTTCTCTAAA } \\
\text { CGAACTTTAAAATCTGTGTGGCTGTCACTCGGCTGCATGCTTAGTGCACTCACGCAGTATAATTAATAC } \\
\text { TAATTACTGTCGTTGACAGGACACGAGTAACTCGTCTATCTTCTGCAGGCTGCTTACGGTTTCGTCCGTG } \\
\text { TTGCAGCCGATCATCAGCACATCTAGGTTTCGTCCGGGTGTGACCGAAAGGTAAG }\end{array}$ \\
\hline 11. & $\begin{array}{l}\text { hsa-miR-4645-3p } \\
\text { AGACAGUAGUUCUUGCCUGGUU }\end{array}$ & 145 & $\begin{array}{l}\text { ATTAAAGGTTTATACCTTCCCAGGTAACAAACCAACCAACTTTCGATCTCTTGTAGATCTGTTCTCTAAA } \\
\text { CGAACTTTAAAATCTGTGTGGCTGTCACTCGGCTGCATGCTTAGTGCACTCACGCAGTATAATTAATACA } \\
\text { TAATTACTGTCGTTGACAGGACACGAGTAACTCGTCTATCTTCTGCAGGCTGCTTACGGTTTCGTCCGTG } \\
\text { TTGCAGCCGATCATCAGCACATCTAGGTTTCGTCCGGGTGTGACCGAAAGGTAAG }\end{array}$ \\
\hline
\end{tabular}


Table 8: CoV-tar-miRNAs targeting the DEGs linked to Diabetes:

\begin{tabular}{|c|c|c|c|c|}
\hline S. No. & $\begin{array}{l}\text { Diabetes- } \\
\text { associated } \\
\text { DEGs }\end{array}$ & $\begin{array}{c}\text { SARS-CoV-2genome's } \\
\text { position targeted by } \\
\text { CoV-tar-miRNAs }\end{array}$ & $\begin{array}{l}\text { CoV-tar-miRNAs } \\
\text { targeting the DEGs }\end{array}$ & $\begin{array}{c}\text { CoV-tar-miRNAs' } \\
\text { raw microarray } \\
\text { expression in } \\
\text { human Pancreas }\end{array}$ \\
\hline \multirow[b]{2}{*}{1.} & \multirow[b]{2}{*}{$\mathrm{CP}$} & 3'UTR & $\begin{array}{l}\text { hsa-miR-466* } \\
\text { hsa-miR-4775** }\end{array}$ & $\begin{array}{l}\text { Unknown } \\
-0.00390\end{array}$ \\
\hline & & 5'UTR & $\begin{array}{l}\text { hsa-miR-3123* } \\
\text { hsa-miR-4691-3p* } \\
\text { hsa-miR-4747-5p } \\
\text { hsa-miR-5196-5p }\end{array}$ & $\begin{array}{l}\text { Unknown } \\
\text { Unknown } \\
10.20753 \\
80.05370\end{array}$ \\
\hline \multirow[t]{2}{*}{2.} & \multirow[t]{2}{*}{ SOCS3 } & 3'UTR & $\begin{array}{l}\text { hsa-miR-1236-3p } \\
\text { hsa-miR-3941* } \\
\text { hsa-miR-4279 } \\
\text { hsa-miR-4717-3p } \\
\text { hsa-miR-5088-5p } \\
\text { hsa-miR-6749-3p* }\end{array}$ & $\begin{array}{c}6.40509 \\
\text { Unknown } \\
3.16020 \\
20.06552 \\
68.77350 \\
\text { Unknown } \\
\end{array}$ \\
\hline & & 5'UTR & $\begin{array}{l}\text { hsa-miR-1303 } \\
\text { hsa-miR-3123* } \\
\text { hsa-miR-3925-5p } \\
\text { hsa-miR-4691-3p* } \\
\text { hsa-miR-7851-3p* }\end{array}$ & $\begin{array}{c}5.12508 \\
\text { Unknown } \\
27.36460 \\
\text { Unknown } \\
\text { Unknown } \\
\end{array}$ \\
\hline \multirow[b]{2}{*}{3.} & \multirow[b]{2}{*}{ AGT } & 3'UTR & hsa-miR-4775* & -0.00390 \\
\hline & & 5'UTR & $\begin{array}{l}\text { hsa-miR-1303 } \\
\text { hsa-miR-298 } \\
\text { hsa-miR-4645-3p } \\
\text { hsa-miR-7851-3p* }\end{array}$ & $\begin{array}{c}5.12508 \\
0.88648 \\
1.34874 \\
\text { Unknown } \\
\end{array}$ \\
\hline \multirow{2}{*}{4.} & \multirow{2}{*}{ PSMB8 } & 3'UTR & $\begin{array}{l}\text { hsa-miR-1236-3p } \\
\text { hsa-miR-4279 } \\
\text { hsa-miR-5088-5p }\end{array}$ & $\begin{array}{l}6.40509 \\
3.16020 \\
68.77350 \\
\end{array}$ \\
\hline & & 5'UTR & $\begin{array}{l}\text { hsa-miR-298 } \\
\text { hsa-miR-3123* } \\
\text { hsa-miR-3925-5p }\end{array}$ & $\begin{array}{c}0.88648 \\
\text { Unknown } \\
27.36460 \\
\end{array}$ \\
\hline 5. & CFB & 3'UTR & hsa-miR-4775** & -0.00390 \\
\hline
\end{tabular}

* Microarray expression data not available on TissueAtlas

** Not expressed in pancreas 